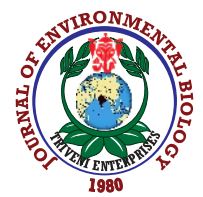

\title{
Mutualistic interactions of green microalga Chlorella sp. with bacterial quorum sensing degrader Bacillus spp isolated from biofloc and freswater prawn Macrobrachium rosenbergii
}

\author{
A.G. Nurarina ${ }^{1}$, H. Aini' ${ }^{2}$, L.H. Ying ${ }^{2}$, I. Ahmad ${ }^{2}$ and I. Natrah ${ }^{* 1,2}$ \\ ${ }^{1}$ Laboratory of Marine Biotechnology, Institute of Bioscience, University Putra Malaysia, Serdang-43400, Selangor, Malaysia \\ ${ }^{2}$ Laboratory of Sustainable Aquaculture, International Institute of Aquaculture and Aquatic Science, Universiti Putra Malaysia, Serdang-43400, \\ Selangor, Malaysia \\ *Corresponding Author Email : natrah@upm.edu.my
}

\section{Abstract}

Aim: Bacterial quorum sensing degrader isolated from biofloc and giant freshwater prawn, Macrobrachium rosenbergii were investigated for mutual interaction with green microalga, Chlorella sp. for potential use of disease control in aquatic environment.

Methodology: Two potential strains of quorum sensing (QS) degrader were successfully isolated from biofloc and giant freshwater prawn, Macrobrachium rosenbergii. Meanwhile, Chlorella sp. was made axenic using 13 to $500 \mathrm{ppm}$ of different antibiotic mixtures (chloramphenicol, tetracycline, enrofloxacin, kanamycin, and neomycin), where interaction of algae with different QS degrader strains, different microbial communities and pathogenic bacterium Aeromonas hydrophila were investigated.

Results: The QS degrader strains were identified as Bacillus subtilis, BP-BFT/1b and Bacillus cereus, BP-MBRG/1b. Growth of Chlorella sp. added with Bacillus subtilis, BP-BFT/1b was higher compared to Bacillus cereus, BP-MBRG/1b. The results showed that the growth of axenic Chlorella sp. improved in the presence of bacteria, including bacterial QS degraders.

Interpretation: There is a potential to incorporate both B. subtilis $\mathrm{BPBFT} / 1 \mathrm{~b}$ and $B$. cereus B PMBRG/1 b in aquaculture systems to overcome invasion of pathogenic bacteria using bacterial QS degrading mechanism.

Key words : Bacterial Quorum sensing, Biofloc, Green microalgae, Macro brachium rosenbergii

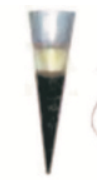

Collection of biofioc and Macrobrachium rosenbergii

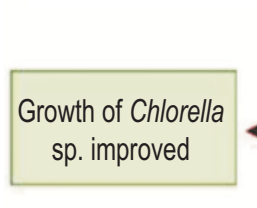

\section{Increased of}

Chlorella sp. growth

followed by sharp decreased on Day 8

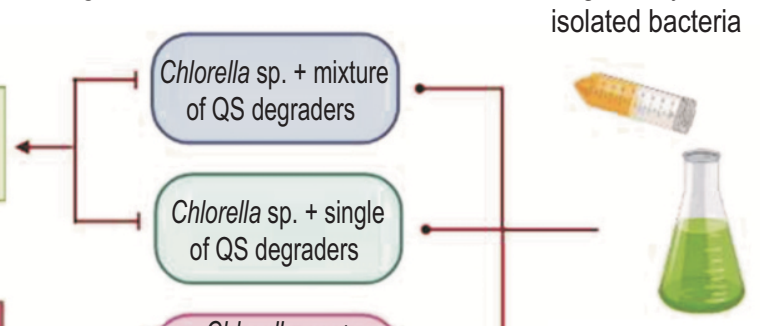

Interation of Chlorella sp.

QS degraders and pathogenic bacteria

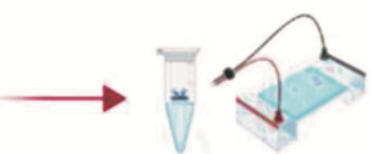

Molecular identification of potential QS degraders

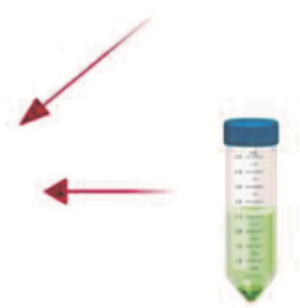

Preparation of axenic Chlorella sp.

How to cite : Nurarina, A.G., L.H. Ying, H.Aini, I. Ahmad and I. Natrah: Mutualistic interactions of green microalga Chlorella sp. with bacterial quorum sensing degrader Bacillus spp. isolated from biofloc and freswater prawn Macrobrachiumrosenbergii. J. Environ. Biol., 41, 1126-1131 (2020). 


\section{Introduction}

In aquaculture, microalgae are the primary food source for a large number of aquatic organisms and they play an important role in their development. Microalgae are cultured as live food for zooplankton, crustaceans, mollusks and fish larvae because they act as source of energy as well as provide essential vitamins and polyunsaturated fatty acids (PUFAs) (Wells et al., 2016). Moreover, microalgae also possess anti-pathogenic activities for bacterial control.

There are several methods to control bacterial diseases in aquaculture such as immunostimulants, vaccines, water disinfection, probiotics including green water technique. Green water can also be a potential technique to control diseases where it improves water quality and enhances aquatic organism resistance to diseases (Chithambaran et al., 2017). Furthermore, previous researches have reported that bacteria greatly affect the growth of microalgae (Grossart et al., 2005), because the organic carbon such as dissolved and particulate particles from live and cell lysis of dead microalgae can promote bacterial growth. In return, bacteria can also enhance the metabolism of microalgae by releasing growth-promoting factors (Fakami et al., 1997). Thus, the use of the consortium may improve aquaculture productions.

Currently, disruption of bacterial cell-to-cell signaling or quorum sensing (QS) is one of the treatments to prevent bacterial disease. Quorum sensing is a mechanism where bacteria are able to coordinate the expression of certain genes in response to the presence of small signal molecules (Hense et al., 2007). It is a type of bacterial cell-to-cell communication that monitors the auto inducer concentration in the environment and control their activity (Miller and Bassler, 2001). Several bacterial pathogens use this mechanism through different signal molecules to regulate virulence gene expression (Pande et al., 2013). To date, the acylated homoserine lactone $(\mathrm{AHL})$ are the most studied bacterial QS signal. Since QS play an important role in pathogenicity towards aquatic host organisms, organisms with QS interference (QSI) activities or Quorum Quenching (QQ) can be used as an alternate source controlling diseases, for which is an ideal choice for aquaculture sector. The aim of this study was to investigate the presence of mutualistic interactions between the green microalga Chlorella sp. with bacterial QS degraders isolated from the biofloc and freshwater prawn Macrobrachium rosenbergii. The positive interactions between both organisms could later be used as one of the biocontrol strategies to control diseases in aquaculture.

\section{Materials and Methods}

Enrichment of QS degraders bacterial strains: Microbial communities from biofloc and gut of freshwater prawn, Macrobrachium rosenbergii were used as the source to isolate degrading strain through enrichment techniques. All samples were incubated for three days in 20 ppm hexanoyl homoserine lactone. Treatment without acylated homoserine lactone served as a control. Each medium was then spread on Trypticase Soy Agar and the cycle was repeated once in three days until bacterial growth in the control medium was totally absent. Colonies isolated from $\mathrm{AHL}$ medium were considered as potential $\mathrm{QS}$ degrader.

AHL degradation assay: The potential QS degrader was examined for $\mathrm{AHL}$ degradation activity using Chromobacterium violaceum (CV026) as reporter strain (McClean et al., 1997). Chromobacterium violaceum act as a generic biosensor that detects and responds to the AHLs signal molecule by inducing the synthesis of purple pigment violacein (Defoirdt et al., 2011).

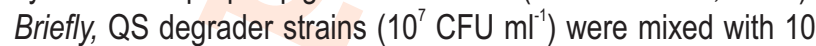
ppm AHL and incubated on the shaker (120 rpm) for $24 \mathrm{hrs}$ at $30^{\circ} \mathrm{C}$. The filtrates $(10 \mu \mathrm{l})$ were then spotted on TSA plate spread with CV026 with 20 ppm kanamycin. The samples were checked at $0,3,6,12,24$ and 48 hrs to observe the degradation level of $\mathrm{AHL}$ concentration. A series of standard solution were also prepared with different $A H L$ concentrations $(0,1,2.5,5,7.5,10$ and $15 \mathrm{ppm})$. After $24 \mathrm{hrs}$, the diameter of purple violacein zone was observed and measured.

Molecular identification of potential QS degrader: Strains were cultured in $10 \mathrm{ml}$ Tryptic Soy Broth (TSB) for $24 \mathrm{hrs}$. Genomic DNA was extracted using GeneJET genomic DNA purification kit (Thermo Scientific, Europe) following the manufacturer's protocol for Gram positive bacteria. DNA quantification and purity check was conducted using BioPhotometer plus (Eppendorf, Germany). Polymerase Chain Reaction (PCR) amplification targeting a 1500 base pair fragment of $16 \mathrm{~S}$ rRNA gene using universal primer, forward 5 - AGA GTT TGA TCC TGG CTC AG-3'; reverse 5'- GGT TAC CTT GTT ACG ACT T-3' (First Base Laboratories, Malaysia) was conducted. The final $25 \mu$ reaction volume of PCR mix contained $1 \mu$ l genomic DNA, $1 \mu$ l of each forward and reverse primer, $1 \mu$ of dNTPs, $5 \mu \mathrm{l}$ of PCR buffer (green), $1 \mu \mathrm{l}$ of $25 \mathrm{mM} \mathrm{MgCl}_{2}, 0.5 \mu \mathrm{l}$ of Taq DNA polymerase and $14.5 \mu \mathrm{l}$ of sterile distilled water (Thermo Scientific, Europe). The PCR reactions were performed on Eppendorf Mastercycler DNA Thermal Cycle (Eppendorf, Germany) with the cycling conditions: initial denaturation at $94^{\circ} \mathrm{C}$ for $10 \mathrm{~min}$, followed by 34 cycles of denaturation at $94.0^{\circ} \mathrm{C}$ for 1 minute, annealing at $54^{\circ} \mathrm{C}$ for $1 \mathrm{~min}$, extension at $72^{\circ} \mathrm{C}$ for $90 \mathrm{sec}$ and final extension at $72^{\circ} \mathrm{C}$ for $10 \mathrm{~min}$. Then, $15 \mu \mathrm{l}$ of PCR products were electrophoresed in $1 \%$ agarose gel ( $90 \mathrm{~V}, 60 \mathrm{~min})$ and was subsequently visualized by UV illumination (Alpha Innotech, USA) after gel red staining. The purified product was sequenced by 1st BASE, Malaysia. The nucleotide sequence result was searched in the GenBank DNA database by using the Basic Local Alignment Search Tool (BLAST) program accessible at the National Center for Biotechnology Information (www.ncbi.nlm. nih.gov). 
Preparation of axenic microalgae Chlorella sp.: Chlorella sp. was isolated from a pond located in the University Agriculture Park, Puchong Selangor Malaysia. Chlorella sp. was prepared as axenic microalgae in Bold Basal Medium by adding five antibiotic mixtures (chloramphenicol, tetracycline, enrofloxacin, kanamycin and neomycin) at three different concentrations (Table 1). The solution was shaken evenly and placed under fluorescent light at of $70 \mu \mathrm{mol}$ photons $\mathrm{m}^{-2} \mathrm{~s}^{-1}$ intensity for a photoperiod of $12 \mathrm{hr}$ light and dark cycle and the pH was adjusted to 8 . After $24 \mathrm{hr}$, the microalgae with antibiotic mixtures were spread on Trypticase Soy Agar and Potato Dextrose Agar to check for bacterial and fungal contaminations. The best antibiotic concentrations were used to obtain axenic Chlorella culture. The residual antibiotics were removed through washing steps for at least three times with centrifugation at $3000 \mathrm{rpm}$ for $10 \mathrm{~min}$. Algal cells were then resuspended in fresh BBM and incubated for at least one week for further growth of axenic Chlorella.

Interaction of bacterial QS degrader with axenic Chlorella sp.: Interaction of axenic Chlorella and QS degraders were tested using QS degrading strains isolated from freshwater prawn, Macrobrachium rosenbergii and biofloc. Xenic Chlorella sp. and pathogenic Aeromonas hydrophila $\mathrm{AH}-1 \mathrm{~N}$ mixed with axenic Chlorella sp. as positive and negative controls were used. Axenic Chlorella sp. was harvested at exponential growth phase and diluted $100 \mathrm{X}$ with sterile BBM to obtain $10^{4} \mathrm{cells} \mathrm{ml}^{-1}$ suspension. Bacterial samples were then added to the microalgal cell at $10^{5}$

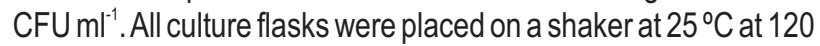
rpm under continuous $70 \mu$ mol photons $\mathrm{m}^{-2} \mathrm{~s}^{-1}$ illumination at $12 \mathrm{hr}$ : $12 \mathrm{hr}$ light: dark cycle. Bacterial concentration and microalgal cell density were monitored every fourth day for 12 days through plate counting and haemocytometer, respectively.

Statistical analysis: Cell density of microalgae and bacteria were analyzed by One-way ANOVA. All data were tested at $5 \%$ level of significance using SPSS (Statistical Package for Social Science) version 21. Significant difference between means were analyzed using Tukey post hoc analysis. The difference was marked by alphabetical notations.

\section{Results and Discussion}

Bacterial QS degraders were isolated from $\mathrm{AHL}$ enrichment medium (+AHL) when no bacterial growth was observed in the control medium (-AHL). Two bacterial strains as potential degraders were successfully isolated each from $M$. rosenbergii and biofloc. Both strains showed AHL degradation activity indicated by loss of purple pigmentation controlled by QS in less than six hours (Fig. 1). This showed that $10 \mathrm{ppm}$ AHL can be fully degraded by the strains. Meanwhile, the concentration of $\mathrm{AHL}$ in control was constant. Both strains were identified as Bacillus subtilis BP-BFT/1b and Bacillus cereus BP-MBRG/1b (Table 2). Different QS degrading bacteria have been isolated from fish and prawn gut (Hong and Cutting, 2009; Tinh et al., 2007) Bacillus sp. are frequently isolated for their use as quorum sensing degrader and probiotic. In the present study, $B$. subtilis $\mathrm{BP}-\mathrm{BFT} / 1 \mathrm{~b}$ and $B$. cereus BP-MBRG/1b bacteria successfully isolated from biofloc and prawn gut showed full AHL degradation activity as indicated by total loss of purple pigmentation. Different species of Bacillus has been identified as QS degraders (Defoirdt et al., 2011; Czajkowski and Jafra, 2009) and species such as B. cereus, $B$. mycoides and $B$. thuringiensis have been shown to degrade AHL through production of AHL lactonase enzyme encoded by gene aiiA (Dong et al., 2000; Bai et al., 2008).

The green microalga Chlorella is among the most common algal species used in aquaculture (Ahmad et al., 2020). Axenic Chlorella sp. can be obtained by mixtures of different antibiotics at the concentration from 13 to $500 \mathrm{ppm}$. No bacterial and fungal growth can be observed after 24 hrs incubation on TSA and PDA media. Meanwhile, bacteria and fungi grew on the agar media inoculated from Chlorella sp. with low concentration antibiotic mixtures (6.3-250 ppm and 3.1-125 ppm) and without any antibiotic mixture after $24 \mathrm{hrs}$ (Table 3 ).

Axenic microalgae are used for varied applications like in production of biofuels and food grade microalgae (Jichang et al., 2015). Antibiotics treatment have been used to effectively remove bacterial contamination from microalgal cultures (Katoh et al., 2012). As bacterial communities associated with different microalgal strains may vary, hence, different kinds and amount of antibiotics are crucial for effective purifying purposes (Jichang et al., 2015). Shishlyannikov et al. (2011) reported that high concentration of antibiotics for a short time can be used to get pure axenic microalgae. Neomycin (Jones et al., 1973), enrofloxacin (Khao and Thao, 2012) and tetracycline are few antibiotics (Xu et al., 2013). However, high concentrations that

Table 1: Concentration of antibiotic (ppm) used for axenic Chlorella culture.

\begin{tabular}{lllll}
\hline Series of antibiotic & \multicolumn{4}{c}{ Concentration $(\mathbf{p p m})$} \\
\cline { 2 - 5 } & A & B & C & Control \\
\hline Chlorampenicol & 15 & 7.5 & 3.75 & 0 \\
Tetracycline & 12.5 & 6.25 & 3.125 & 0 \\
Enrofloxacin & 320 & 160 & 80 & 0 \\
Kanamycin & 100 & 50 & 25 & 0 \\
Neomycin & 500 & 250 & 125 & 0 \\
\hline
\end{tabular}


Table 2 : Identification of the isolates based on NCBIBLAST

\begin{tabular}{llllc}
\hline Strain & Isolate & Source & Accession n $^{\text {(1 }}$ & Similarity $(\%)$ \\
\hline BP-BFT/1b & Bacillus subtilis & Biofloc & JN128239 & $92 \%$ \\
BP-MBRG/1b & Bacillus cereus & M. rosenbergii & JF343136 & $86 \%$ \\
\hline
\end{tabular}

${ }^{1}$ GenBank accession numbers

Table 3 : Different antibiotic treatments to obtain axenic Chlorella sp. after 24 hours

\begin{tabular}{|c|c|c|}
\hline Series of antibiotic & Number of bacterial single colony (CFU ml ${ }^{-1}$ ) & Number of fungus single colony (CFU ml') \\
\hline $\mathrm{A}(13 \mathrm{ppm}-500 \mathrm{ppm})$ & - & - \\
\hline $\mathrm{B}(6.3 \mathrm{ppm}-250 \mathrm{ppm})$ & $>300$ & $>300$ \\
\hline C (3.1 ppm-125 ppm) & $>300$ & $>300$ \\
\hline Control (0 ppm) & $6.5 \times 10 u$ & $>300$ \\
\hline
\end{tabular}

-No colony observed

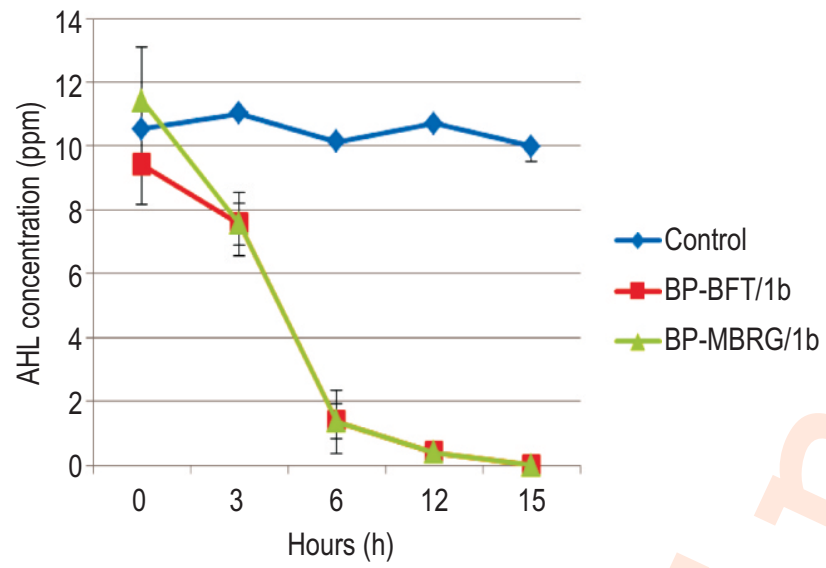

Fig. 1 : AHL Concentration (ppm) of BP-BFT/1b and BP-MBRG/1b samples within 15 hours in Luria Bertani containing $10 \mathrm{ppm} A H \mathrm{HL}$.

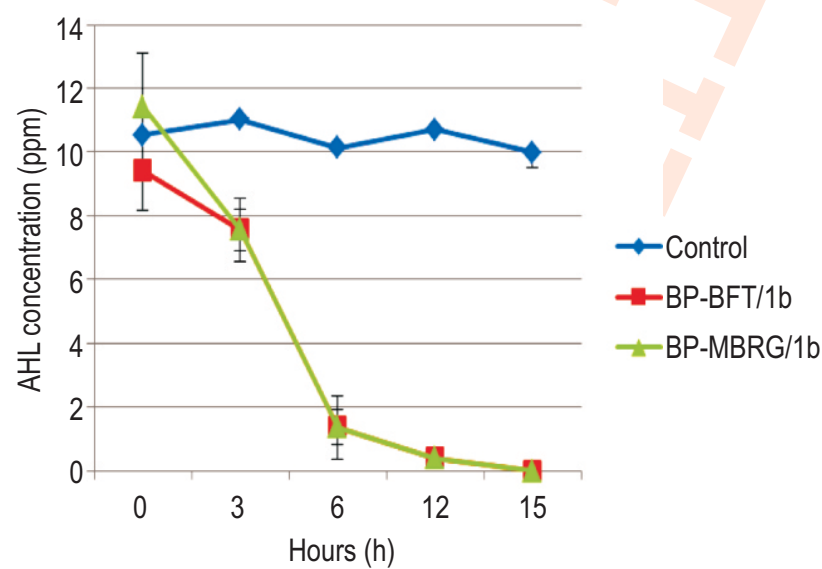

Fig. 3 : Specific Growth Rate of Chlorella sp. inoculated with and without single and mixtures of $\mathrm{QS}$ degraders (BP-MBRG/1b and BP-BFT/1b) and pathogenic bacteria (A. hydrophila) during 12 days of culture period.

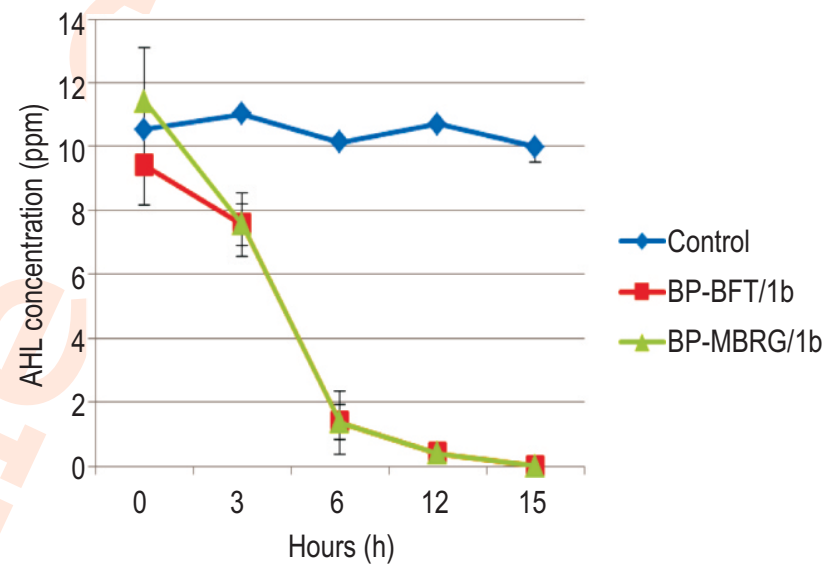

Fig. 2 : Growth performance of Chlorella sp. inoculated with single and mixtures of QS degraders (BP-MBRG/1b and BP-BFT/1b) and pathogenic bacteria (A. hydrophila) during 12 days of culture period.

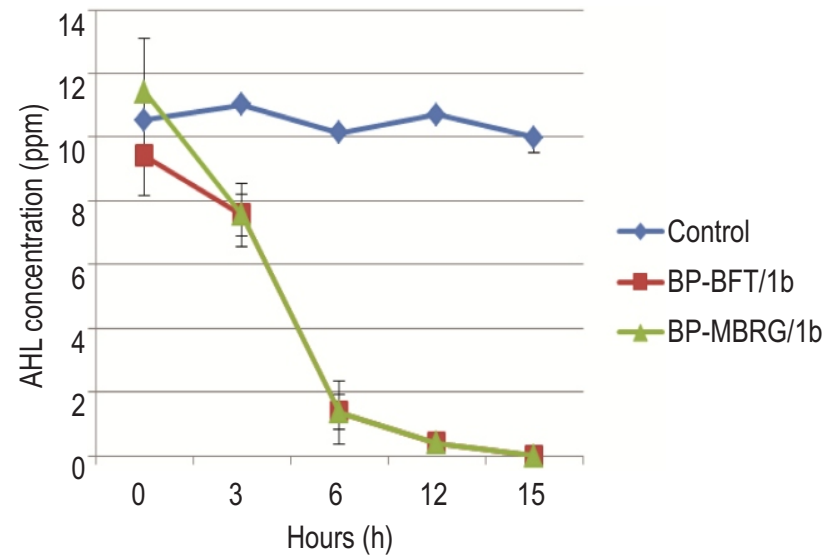

Fig. 4 : Bacterial plate count in Chlorella sp. inoculated with and without single and mixtures of QS degraders (BP-MBRG/1b and BP-BFT/1b) and pathogenic bacteria ( $A$. hydrophila) during 12 days of culture period. 
have been tested not only affect the associated microorganisms but can be toxic to algal cells (Khao and Thao, 2012; Xu et al., 2013).

The co-culture between microalgae and both QS degrader Bacillus strains BP-BFT/1b and BP-MBRG/1b gradually increased the growth of Chlorella sp. during 12 days culture period. However, co-culture of Chlorella sp. with BP-BFT/1b strain showed higher growth compared to BP-MBRG/1b strain. However, mixtures of both strains showed slightly lower Chlorella sp. growth than BP-BFT/1b alone. On the other hand, co-culture with pathogenic $A$. hydrophila $\mathrm{AH}-1 \mathrm{~N}$ increased algae growth in the beginning of culture, followed by a sharp decrease from eighth day onwards (Fig. 2). In contrast to all treatments, the highest Chlorella sp. cell densities were from xenic algal culture (data not shown). Similarly, the specific growth rate (SGR) of Chlorella sp. was also higher in xenic culture (24\%) compared to other treatments (less than 14\% SGR) (Fig. 3). In parallel, the highest bacterial cell densities were obtained in xenic culture, which increased gradually from Day 0 to Day 12 . No bacterial colony was observed in axenic Chlorella sp. culture. Meanwhile, the density of all bacterial QS degraders dropped two logs below the initial inoculum. The density, however, stagnated throughout the experiment. Initially, A. hydrophila showed slight increase in the growth later it was noted that the density started to decline from Day 4 onwards (Fig. 4).

Existence of BP-BFT/1b and BP-MBRG/1b significantly enhanced the specific growth of xenic Chlorella $\mathrm{sp}$. when compared with axenic conditions. The results are in agreement with the findings of Hernandez et al. (2008), who quantified the enhanced growth in Chlorella sp. and combined it with rhizobacteria Bacillus pumilus in a short-term incubation. This enhanced the absorption of nitrogen and phosphorus through different metabolic pathways by microalgal cells. Qu et al. (2014) also reported similar results. The growth of $C$. vulgaris was promoted when co-cultured with Bacillus sp., where the maximum cell concentration was observed on day 8 and thereafter decreased due to resource competition. In nature, bacteria and microalgae co-exists together and interact symbiotically. Bacteria utilizes products from microalgae cells while bacteria contributed organic nutrient rich in carbon, nitrogen and other growth factors for microalgae (Fukami 1997; Grossart and Simon, 2007; Grossart et al., 2005). However, the growth of microalgae can be inhibited due to several factors like bacteria producing antibiotics (Rooney-Varga et al., 2005), algicidal extracellular metabolites (Munoz and Guieysse, 2006), breaking respiratory chain or inhibiting cell wall synthesis (Zhao et al., 2012) and competition of nutrients (Trabelsia and Rassoulzadegana, 2011).

It was observed that co-existence of bacteria and microalgae showed both positive and negative interactions during culture. High bacterial density in xenic culture was probably due to availability of organic matter released from Chlorella sp. that promoted bacterial growth. Microalgae excrete carbon sources or other products that enhance bacterial activity. Conversely, bacterial growth can be suppressed due to secretion of antibiotics from Chlorella sp. (Grossart and Simon 2007) and also due to competition for resources (Qu et al., 2014). According to Lekunberri et al. (2011), bacteria and microalgae may also compete for limiting nutrients such as phosphate. In the natural environment, microalgae are always in association with bacteria, fungi and other microorganisms (Tujula et al., 2010). The relationship between microalgae and bacteria can be either symbiotic or inhibitory.

This research showed that axenic Chlorella sp. can be obtained using combination of $13 \mathrm{ppm}$ to $500 \mathrm{ppm}$ of chloramphenicol, tetracycline, enrofloxacin, kanamycin and neomycin mixtures. This study also showed that there is a mutualistic interaction between microalga Chlorella and bacterial quorum sensing degraders. The presence of bacteria stimulated the microalgal growth and vice versa. However, since inhibitory activities were also observed, the use of consortium needs to be further investigated. This study is important to understand how associated bacteria and microalgae influence the growth of each other. The right combination of algae and bacteria could significantly improve their productivity and efficiency as biocontrol agents against pathogen in aquaculture.

\section{Acknowledgments}

Financial support by Universiti Putra Malaysia (UPM) through Research University Grant Scheme (GPIPS/2016/9469500). This study was also supported by the "Matching Fund SATREPS-COSMOS (JICA-JST) grant from the Ministry of Higher Education, Government of Malaysia" awarded to the Institute of Bioscience (IBS), Universiti Putra Malaysia (UPM).

\section{References}

Ahmad, M. T., M. Shariff, F.M. Yusoff, Y.M. Goh and S. Banerjee: Applications of microalga Chlorella vulgaris in aquaculture. Review. Aquacul., 12, 328-346 (2020)

Bai, F., Y. Han, J. Chen and X. Zhang: Disruption of quorum sensing in Vibrio harveyi by the AiiA protein of Bacillus thuringiensis. Aquacult., 274, 36-40(2008).

Chithambaran, S., M. Harbi, M. Broom, K. Khobrani, O. Ahmad, H. Farrani, A. Sfyani and N. Ayaril: Green water technology for the production of Pacific white shrimp Penaeus vannamei (Boone, 1931). Indian J. Fish., 64, 43-49 (2017).

Czajkowski, R. and S. Jafra: Quenching of acyl-homoserine lactone dependent quorum sensing by enzymatic disruption of signal molecules. Acta Biochem. Poll., 56, 1-16 (2009).

Defoirdt, T., N. Boon, P. Bossier and W. Verstraete: Disruption of bacterial quorum sensing: An unexplored strategy to fight infections in aquaculture. Aquaculture, 240, 69-88 (2004).

Defoirdt, T., L.D. Thanh, B.V. Delsen, P.D. Schryver, P. Sorgeloos, N. Boon and P. Bossier: N-acylhomoserine lactone-degrading 
Bacillus strains isolated from aquaculture animals. Aquaculture, 311, 1-4 (2011).

Dong, Y.H., J.L. Xu, X.Z. Li and L.H. Zhang: AiiA, an enzyme that inactivates the acyl homoserine lactone quorum-sensing signal and attenuates the virulence of Erwinia carotovora. Proceed. Nati. Acad. Sci., 97, 3526-3531 (2000).

Fukami, K., T. Nishijima and Y. Ishida: Stimulative and inhibitory effects of bacteria on the growth of microalgae. Hydrobiol., 358, 185-191 (1997).

Grossart, H.P., F. Levold, M. Allgaier, M. Simon and T. Brinkhoff: Marine diatom species harbour distinct bacterial communities. Environ. Microbiol., 7, 860-873 (2005)

Grossart, H.P. and M. Simon: Interactions of planktonic algae and bacteria: effects on algal growth and organic matter dynamics. Aquat. Microb. Ecol., 47, 163 (2007).

Hense, B.A., C. Kuttler, J. Muller, M. Rothballer, A. Hartmann and J.U. Kreft: Does efficiency sensing unify diffusion and quorum sensing. Nat. Rev. Microbiol., 5, 230-239 (2007).

Hernandez, J., L.E. de-Bashan, D.J. Rodriguez, Y. Rodriguez and Y. Bashan: Growth promotion of the freshwater microalga Chlorella vulgaris by the nitrogen-fixing, plant growth-promoting bacterium Bacillus pumilus from arid zone soils. Eur. J. Soil. Biol. 45, 88-93 (2008)

Hong, H.A, L.H. Duc and S.M. Cutting: The use of bacterial spore formers as probiotics. FEMS Microbial., 29, 813-835 (2009).

Jichang, H., S. Wang, L. Zhang, G. Yang, L. Zhao and K. Pan: A method of batch-purifying microalgae with multiple antibiotics at extremely high concentrations. Chin. J. Oceanol. Limn., 34, 79-85 (2016).

Jones, A.K., M.E. Rhodes and S.C. EvansL The use of antibiotics to obtain axenic cultures of algae. BrPhycol., 8, 185-196 (1973).

Katoh, H., J. Furukawa, K. Tomita-Yokotani and Y. Nishi: Isolation and purification of an axenic diazotrophic drought-tolerant cyanobacterium, Nostoccommune , from natural cyanobacterial crusts and its utilization for field research on soils polluted with radioisotopes. Biochimicaet. Biophysica. Acta, 1817, 1499-1505 (2011).

Khoa, N.L.N. and N.T.P. Thao: Assessment of the fate and effects of antibiotics on freshwater ecosystems surrounding catfish farms in Mekong delta (Vietnam). MargotANDRIEU, 73 (2012)

Lekunberri, I., T. Lefort, C. Romera-Castillo, C. Cardelús, M. Coll-Lladó, C. Ruiz-González and J.M. Gasol: Relationship between induced phytoplankton blooms and the structure and dynamics of the freeliving heterotrophic bacterial community. Mar. Ecol. Prog. Ser., 448, 23-37 (2011).

McClean, K.H., M.K. Winson, L. Fish, A. Taylor, S.R. Chhabra, M. Camara, M. Daykin, J.H. Lamb, S. Swift, B.W. Bycroft, G.S.A.B Stewart and P. Williams: Quorum sensing and Chromobacterium violaceum: Exploitation of violacein production and inhibition for the detection of $\mathrm{N}$-acylhomoserine lactones. Microbiol., 143, 37033711 (1997).
Miller, M.B. and B.L. Bassler: Quorum sensing in bacteria. Annu. Rev. Microbiol., 55, 165-199 (2001).

Muñoz, R. and B. Guieysse: Algal-bacterial processes for the treatment of hazardous contaminants: A review. Water Research, 40, 2799$2815(2006)$.

Oswald, W.J.: My sixty years in applied algology. J. Appl. Phycol., 15, 99106 (2003).

Pande, G.S.J., A.A. Scheie, T.Benneche, M. Wille, P. Sorgeloos, P. Bossier and T. Defoirdt: Quorum sensing-disrupting compounds protect larvae of the giant freshwater prawn Macrobrachium rosenbergii from Vibrio harveyi infection. Aquaculture, 406, 121124 (2013).

Qu, L., R. Wang, P. Zhao, R. Chen, W. Zhou, L. Tang and X. Tang: Interaction between Chlorella vulgaris and bacteria: Interference and resource competition. Acta. Oceanologica. Sinica, 33, 135140 (2014).

Rooney-Varga, J.N., M.W. Giewat, M.C. Savin, S. Sood, M. LeGresley and J.L. Martin: Links between phytoplankton and bacterial community dynamics in a coastal marine environment. Microbial. Ecol., 49, 163-175 (2005).

Shishlyannikov, S.M., Y.R. Zakharova, N.A. Volokitina, I.S. Mikhailov, D.P. Petrova and Y.V. Likhoshway: A procedure for establishing an axenic culture of the diatom Synedraacus subsp. radians (Kütz.) Skabibitsch. from Lake Baikal. Limnol. Oceanogr.: Meth, 9, 478484 (2011).

Tinh, N.T.N., R.A.Y.S.A. Gunasekara, N. Boon, K. Dierkens, P. Sorgeloos and $\mathrm{P}$. Bossier: $\mathrm{N}$-acyl homoserine lactone-degrading microbial enrichment cultures isolated from Penaeus vannamei shrimp gut and their probiotic properties in Brachionus plicatilis cultures. FEMS Microbial. Ecol., 62, 45-53 (2007).

Trabelsi, A. and F. Rassoulzadegan: Inorganic nutrient control of dissolved organic carbon (DOC) dynamics in NW Mediterranean waters: An experimental approach. Mar. Biol. Res., 7, 667-676 (2011).

Tujula, N.A., G.R. Crocetti, C. Burke, T. Thomas, C. Holmström and S. Kjelleberg: Variability and abundance of the epiphytic bacterial community associated with a green marine Ulvacean alga. The ISME J., 4, 301-311 (2009).

Wells, M.L., P. Potin, J.S. Craigie, J.A. Raven, S.S. Merchant, K.E. Helliwell, A.G. Smith, M.E. Camire and S.H. Brawley: Algae as nutritional and functional food source: Revisiting our understanding. J. App. Phycol., 29, 949-982 (2016).

Xu, D.M., Y.H. Wang and G.W. Rao: Cellular response of freshwater green algae to the toxicity of tetracycline antibiotic. Biol. Environ. Eng., 34, 3386-3390 (2013).

Zhao, S., W.B. Pan and C. Ma: Stimulation and inhibition effects of algaelytic products from Bacillus cereus strain L7 on Anabaena flosaquae. J. Appl. Phycol., 24, 1015-1021 (2012). 